\begin{tabular}{|c|c|c|}
\hline 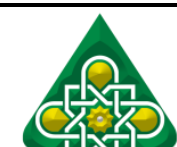 & $\begin{array}{c}\text { Bioeduca: Jurnal Pendidikan Biologi } \\
\text { http://journal.walisongo.ac.id/index.php/bioeduca } \\
\text { ISSN 2714-8009 (print), 2715-7490 (online) }\end{array}$ & B'BEDƯCA \\
\hline WALISONGO & $\begin{array}{c}\text { Volume 2, Nomor 2, Tahun } 2020 \\
\text { Hal.79 - } 86\end{array}$ & \\
\hline
\end{tabular}

\title{
Kajian Etnosains Tradisi Maauwo di Danau Bakuok Sebagai Sumber Pembelajaran Biologi
}

\author{
Aldeva Ilhami ${ }^{*}$, Revi Syahvira ${ }^{2}$, Ukhti Maisarah ${ }^{3}$, Diniya Diniya ${ }^{4}$ \\ 1,2,3,4Tadris IImu Pengetahuan Alam, Universitas Islam Negeri Sultan Syarif Kasim Riau
}

*Email: aldeva.ilhami@uin-suska.ac.id

\begin{tabular}{|c|c|}
\hline Informasi Artikel & ABSTRAK \\
\hline $\begin{array}{l}\text { Submit: } 01-09-2020 \\
\text { Diterima: } 29-09-2020 \\
\text { Dipublikasikan: } 11-10-2020\end{array}$ & $\begin{array}{l}\text { Pembelajaran biologi tidak dapat dipisahkan dengan konteks } \\
\text { lingkungan termasuk kearifan lokal. Tradisi maauwo merupakan } \\
\text { kegiatan penangkapan ikan hanya boleh dilakukan sekali dalam } \\
1 \text { tahun di kabupaten kampar. Tujuan penelitian ini adalah } \\
\text { menganalisis dan merekonstruksi pengetahuan sains ilmiah } \\
\text { (scientific knowledge) dari tradisi maauwo. Penelitian ini } \\
\text { menggunakan pendekatan kualitatif berbasis etnosains dengan } \\
\text { metode wawancara dan observasi. Analisis data menggunakan } \\
\text { model Miles-Huberman yang meliputi reduksi data, penyajian } \\
\text { data, penarikan kesimpulan dan verifikasi. Berdasarkan hasil } \\
\text { penelitian menunjukkan bahwa tradisi maauwo sebagai salah } \\
\text { bagian dalam sistem pengelolaan sumber daya perairan di } \\
\text { danau bakuok. Masyarakat dilarang mengambil ikan dalam } \\
\text { periode tertentu, dilarang untuk menyentrum maupun meracuni } \\
\text { ikan serta menanami sawit di tepi danau bakuok. Penerapan } \\
\text { aturan tersebut memiliki nilai konservasi lingkungan untuk } \\
\text { menjaga keseimbangan ekologi di danau bakuok. Kearifan lokal } \\
\text { maauwo di danau bakuok memiliki potensi sebagai sumber } \\
\text { belajar biologi pada materi pelestarian ekosistem dan } \\
\text { pencemaran lingkungan. } \\
\text { Kata kunci: pembelajaran biologi; kearifan lokal; maauwo; } \\
\text { etnosains. }\end{array}$ \\
\hline Penerbit & $\begin{array}{ll}\text { ABSTRACT } \\
\end{array}$ \\
\hline $\begin{array}{l}\text { Program Studi Pendidikan } \\
\text { Biologi, Fakultas Sains dan } \\
\text { Teknologi, UIN Walisongo } \\
\text { Semarang }\end{array}$ & $\begin{array}{l}\text { Biology learning cannot be separated from the environmental } \\
\text { context, including local wisdom. The maauwo tradition is a fishing } \\
\text { activity that can only be done once a year in Kampar district. The } \\
\text { purpose of this research is to analyze and reconstruct scientific } \\
\text { knowledge (scientific knowledge) from the Maauwo tradition. This } \\
\text { study used a qualitative approach based on ethnoscience with } \\
\text { interview and observation methods. We used the Miles- } \\
\text { Huberman model to analyze the data which includes data } \\
\text { reduction, data presentation, drawing conclusions and } \\
\text { verification. Based on the research results, it showed that the } \\
\text { Maauwo tradition is a part of the marine resource management } \\
\text { system in Bakuok Lake. The community is prohibited from taking } \\
\text { fish within a certain period, it is prohibited to electrocute or } \\
\text { poison the fish and plant oil palms on the shores of the Bakuok } \\
\text { lake. The application of this regulation has environmental } \\
\text { conservation value to maintain ecological balance in Bakuok } \\
\text { lake. The local wisdom of Maauwo in Danau Bakuok has the } \\
\text { potential to be a source of learning biology on materials for } \\
\text { preserving ecosystems and environmental pollution. } \\
\text { Keywords: biology learning; local wisdom; maauwo;etnoscience. }\end{array}$ \\
\hline
\end{tabular}

Copyright (02020, Bioeduca: Journal of Biology Education

Aldeva Ilhami et al. - Kajian Etnosains Tradisi Maauwo di Danau Bakuok sebagai Sumber 


\section{PENDAHULUAN}

Indonesia memiliki beragam budaya dan kearifan lokal dari berbagai suku dan etnis. Secara umum, kearifan lokal dapat diartikan sebagai bentuk kebijaksanaan yang didasari nilai-nilai kebaikan yang dipercaya masyarakat setempat. Budaya lokal tersebut berasal dari nenek moyang terdahulu yang masih dipertahankan sampai saat ini. Supaya budaya lokal tidak punah, pelestarian agar tetap terus bertahan seiring perkembangan zaman (Brata, 2016). Nilai-nilai luhur perlu ditanamkan dan disosialisasikan, salah satunya melalui proses pembelajaran di sekolah. Oleh karena itu, penelusuran atau penggalian mengenai budaya lokal atau pengetahuan asli (indigenous knowledge) suatu masyarakat sangat penting untuk diteliti. Hal ini dapat menjadi salah satu sumber belajar berbasis pengetahuan lokal (Oktavianti, 2018; Pieter, 2017).

Belajar merupakan cara untuk mendapatkan pengetahuan, pemahaman dan penguasaan konsep melalui pengalaman (Hergenhanh \& Olson, 2008). Kemudian menurut Sudjana \& Rivai (2007) sumber belajar merupakan segala sesuatu yang dapat didayagunakan baik secara langsung maupun tidak langsung. Hal ini menunjukkan bahwa siswa memperoleh pengetahuan tidak hanya melalui pembelajaran di sekolah akan tetapi juga melalui proses pengamatan dari lingkungan sekitar seperti kearifan lokal setempat.. Guru diharapkan menghadirkan isu kontekstual yang berhubungan erat dengan kehidupan sehari hari siswa dan membimbing siswa untuk merekonstruksi pengetahuan berbasis kearifan lokal menjadi pengetahuan ilmiah mekalui pendekatan kontekstual (Harefa, 2017; Rahmi \& Rosdiana, 2018). Akan tetapi pembelajaran sains di sekolah kurang memperhatikan budaya lokal yang berkembang di masyarakat yang ada karena keterbatasan guru dalam mengaitkan konsep, proses, dan konteks sehingga pemahaman siswa tentang fenomena alam menjadi tidak bermakna (Mulyani \& Julianto, 2019)

Etnosains merupakan kegiatan mentransformasikan sains asli (pengetahuan yang berkembang di masyarakat) menjadi sains ilmiah (Rahayu \& Sudarmin, 2015). Sains asli berkaitan dengan pengetahuan sains yang diperolehnya melalui budaya oral di tempat yang sudah lama ditempatinya (Snively \& Corsiglia, 2001). Adapun ruang lingkup dari pengetahuan sains asli (indigenous science) meliputi bidang sains, pertanian, ekologi, obat-obatan dan tentang manfaat dari flora dan fauna (Battiste, 2005). Dalam hal ini nilai-nilai yang dipercayai oleh masyarakat adalah bagian dari pengertian sains asli, dimana sains asli dapat direkonstruksi menjadi sains ilmiah. Sains ilmiah adalah konsep, prinsip, teori, ataupun hukum-hukum yang reprodusibel dan telah diakui oleh komunitas ilmiah. Sehingga rekonstruksi sains asli merupakan penataan ulang konsep-konsep yang ada di dalam sains asli, diterjemahkan ke dalam sains barat atau sains ilmiah. Pada saat ini sains asli yang merupakan subbudaya dari kelompok masyarakat mulai mendapat perhatian dari para pakar pendidikan sains maupun guru-guru sains di Indonesia (Harefa, 2017). Adanya pemaknaan pengetahuan lokal menjadi sains ilmiah bermanfaat dalam mendukung pencapaian konsep konsep sains dalam pembelajaran. 
Penggunaan lingkungan sekitar memiliki kontribusi positif terhadap pencapaian hasil belajar siswa. Penelitian yang dilakukan oleh Irawan \& Muhartati, 2019 menunjukkan masyarakat Bintan di Kepulauan Riau memiliki banyak kearifan lokal dan etnosains berupa aktivitas berkarang dan menyondong ikan yang dapat dihubungkan dengan sains biologi modern. Kemudian penelitian yang dilakukan oleh Elsera (2019) di kabupaten Bintan, Kepulauan Riau menyatakan bahwa sains asli yang dimiliki oleh masyarakat Orang Suku Laut dapat dimanfaatkan untuk rancangan proses pembelajaran sains di sekolah. Penelitian yang dilakukan oleh Harefa (2017) juga menyebutkan lingkungan sosial-budaya siswa sangat perlu diperhatikan dalam mengembangkan pembelajaran sains di sekolah. Hal ini dikarenakan terpendamnya sains asli dalam lingkungan masyarakat dapat berguna bagi sains ilmiah dan kehidupan siswa. Dengan demikian, beberapa penelitian tentang pemanfaatan lingkungan dalam pembelajaran membuktikan adanya pengaruh yang sangat baik (Yuliana, 2017). Selain itu, pembelajaran sains yang mampu menjembatani perpaduan antara budaya siswa dengan budaya ilmiah di sekolah akan membuat proses belajar siswa menjadi lebih efektif.

Provinsi Riau adalah salah satu Provinsi yang terletak di bagian tengah Pulau Sumatera. Provinsi Riau berbatasan pada bagian utara dengan Provinsi Sumatera Utara, Provinsi Jambi dibagian Selatannya dan di sebelah Barat berbatasan dengan Provinsi Sumatera Barat. Provinsi Riau Secara etimologi, berasal dari bahasa Portugis, "Rio", yang artinya sungai. Riau dirujuk hanya ke wilayah yang dipertuan muda (Raja Bawahan Johor) di Pulau Penyengat.Riau merupakan penggabungan dari kerajaan Melayu yang pernah berjaya di wilayah ini, yaitu Kerajaan Indragiri (1658-1838), Kerajaan Siak Sri Indrapura (1723-1858), Kerajaan Pelalawan (15301879), Kerajaan Riau-Lingga (1824-1913) dan beberapa kerajaan kecil lainnya. Mayoritas etnis yang terdapat di provinsi Riau adalah etnis melayu (Diskominfo, 2020).

Masyarakat Melayu Riau memiliki sistem budaya dalam pengelolaan lingkungan. Salah satu kearifan lokal berkaitan dengan pelestarian lingkungan misalnya tradisi penanaman rumbia. Tradisi menanam rumbia ditepi ladang dipercaya masyarakat setempat untuk menjaga keseimbangan lingkungan. Tanaman rumbia membuat ladang mereka mendapat cadangan simpanan air ketika musim kemarau karena tanaman ini dapat menyimpan air. Sementara itu, rumbia juga dapat dijadikan barang anyaman, diantaranya dibuat jadi ago untuk alat pengangkut padi (Thamrin, 2014). Kemudian, tradisi lainnya yaitu tradisi tidak memberantas musang. Menurut pengetahuan masyraakat setempat bahwa musang suka memakan buahbuahan seperti buah enau dan kopi. Hal ini akan sangat menguntungkan karena musang membuang kotoran yang mengandung biji enau atau kopi. Pohon enau dan kopi berpotensi besar untuk tumbuh di tempat musang mengeluarkan kotorannya. (Thamrin, 2014).

Salah satu kearifan lokal masyarakat riau adalah tradisi maauwo. Tradisi ini berupa penangkapan ikan yang dilakukan secara bersama sama yang dilaksanakan di Danau Bakuok. Danau ini merupakan salah satu contoh suaka perikanan di 
kabupaten Kampar, provinsi Riau yang menerapkan sistem pengelolaannya berdasarkan hukum adat. Kegiatan penangkapan ikan secara adat yang dilakukan 1 tahun sekali sehingga dikenal dengan istilah "Maauwo". Berdasarkan latar belakang tersebut, penelitian ini bertujuan untuk menganalisis dan merekonstruksi pengetahuan masyarakat (indigeneous science) tentang tradisi maauwo menjadi pengetahuan sains (scientific knowledge).

\section{METODE PENELITIAN}

Penelitian ini menggunakan pendekatan kualitatif berbasis etnosains. Lokasi penelitian terletak di desa Aursati, Kabupaten Kampar. Metode pengumpulan data dilakukan dengan observasi dan wawancara yang dilaksanakan pada bulan Mei-Juni 2020. Kegiatan observasi dilakukan dengan pengamatan secara langsung lokasi Danau Bakuok Desa Aursati sebagai tempat dilakukan tradisi maauwo. Wawancara bertujuan untuk mendapatkan informasi tentang tradisi maauwo di danau Bakuok, desa Aur Sati. Narasumber yang digunakan adalah tokoh adat, pemerintahan desa dan masyarakat untuk memperoleh informasi secara komprehensif tentang tradisi maauwo dan sistem pengelolaan danau bakuok Bakuok di Desa Aursati. Proses rekonstruksi pengetahuan lokal (indigineous local) difokuskan pada kepercayaan masyarakat dan aturan yang diberlakukan di danau bakuok. Analisis data menggunakan model Miles-Huberman yang meliputi reduksi data, penyajian data, penarikan kesimpulan dan verifikasi.

\section{HASIL PENELITIAN DAN PEMBAHASAN}

Maauwo adalah sebuah tradisi menangkap ikan oleh masyarakat Kampar di danau bakuok. Tradisi ini dilakukan sekali dalam setahun. Ada beberapa tahapan yang dilakukan di danau bakuok sebelum dilaksanakan tradisi maauwo. Tokoh adat dan pemerintah desa melaksanakan musyawarah untuk menetapkan larangan pengambilan ikan di danau setelah adanya bibit ikan yang masuk ke danau bakuok. Adapun bibit ikan dapat diperoleh secara alami yaitu banjir yang memungkinkan masuknya ikan dari sungai Kampar dan secara buatan melalui pelepasan bibit ikan melalui bantuan dari pemda setempat.

"untuk tradisi maauwo, ada dua cara masuknya ikan ke dalam danau bakuok yaitu yang pertama mengharapkan banjir, seketika banjir bibit ikan masuk dari sungai Kampar, dan yang kedua ada bantuan bibit ikan dari pemerintah. kalau sudah ada bibit ikannya, ninik mamak segera bermusyawarah rapat dengan aparatur desa" (Abdu Rajab, 2020).

Masyarakat dilarang untuk mengambil ikan di danau bakuok setelah ditetapkan aturan larangan berdasarkan hasil keputusan tokoh adat dan pemerintah desa. Di sekitaran danau akan diberikan tanda pelarangannya agar masyarakat sekitar mengetahui bahwa larangan penangkapan ikan di danau sudah diberlakukan. Salah satu tradisi masyarkat setempat dengan pembacaan doanya supaya diharakan keberkahan. Bagi masyarakat yang mengambil ikan selama proses larangan maka akan diberlakukan hukuman baik secara aturan adat ataupun pidana. 
"Bagi yang mengambil ikan akan didenda sesuai aturan adat. Ninik mamak yang beersangkutan akan dipanggil dan semua ninik mamak akan berkumpul untuk memutuskan hukuman bagi pencuri ikan itu. Hukumannya tergantung banyak ikan yang diambil, kemudian tergantung perbuatannya. Hukuman dapat berupa denda satu ekor kambing, Kalau perbuatannya udah sering ngambil denda jadi berat, bisa jadi kerbau. Pelaku juga dapat dihukum melalui aturan negara karena berkaitan masalah pidana" (Abdu Rajab, 2020).

Tradisi maauwo dijadikan sebagai festival tahunan bagi masyarakat di desa Aur Sati dan masyarakat Kampar pada umumnya. Masyarakat sudah diperbolehkan untuk mengambil ikan di danau bakuok dengan ketentuan yang telah ditetapkan. Pada umumnya masyarakat menggunakan sampan dan alat penangkap kan tradisonal. Beberapa alat tangkap yang digunakan diantaranya jala, jaring, dan berbagai macam alat tangkap ikan tradisional lainnya. Adapun larangan metode pengambilan ikan dengan menggunakan zat kimia beracun dan alat setrum ikan. Kemudian pada saat festival hampir seluruh permukaan danau dipenuhi oleh sampan masyarakat setempat. Setiap sampan terdiri dari beberapa orang yang memiliki tugas masing-masing seperti ada yang bertugas mendayung sampan dan ada yang menyebarkan jala untuk menangkap ikan. Sebagian masyarakat ada juga yang menggunakan alat pancing untuk menangkap ikan. Adapun jenis ikan yang ada di dalam Danau Bakuok yaitu, ikan nila, gurami, gabus, patin, baung, motan.

Berdasarkan hasil observasi dan wawancara tentang tradisi Maauwo, pengetahuan asli masyarakat setempat (indigenous science) memiliki nilai kearifan lokal yang masih dipertahankan sampai saat ini. Pengetahuan masyarakat tersebut dapat direkonstruksi menjadi pengetahuan ilmiah (science) sebagaimana yang disajikan pada Tabel 1

Tabel 1. Rekonstruksi Sains Asli ke Sains IImiah

\begin{tabular}{|c|c|}
\hline Sains Asli Masyarakat & Sains IImiah \\
\hline $\begin{array}{l}\text { Masyarakat desa meyakini bahwa } \\
\text { setiap tahun sungai Kampar akan } \\
\text { terjadi banjir yang berpotensi } \\
\text { membawa bibit ikan masuk ke } \\
\text { danau Bakuok. }\end{array}$ & $\begin{array}{l}\text { Danau Bakuok ini terbentuk akibat terputusnya aliran sungai } \\
\text { Kampar Kanan. Jarak antara danau Bakuok dengan sungai } \\
\text { Kampar tidak terlalu jauh sehingga ketika banjir air sungai } \\
\text { Kampar meluap dan membawa seluruh material termasuk } \\
\text { ikan didalamnya. }\end{array}$ \\
\hline $\begin{array}{l}\text { Dilarang menangkap ikan selama } \\
4-5 \text { bulan, alasan masyarakat agar } \\
\text { ikannya banyak ketika saat acara } \\
\text { tradisi maawuo. }\end{array}$ & $\begin{array}{l}\text { Dilarang menangkap ikan selama waktu yang ditetapkan } \\
\text { dapat memberikan waktu untuk ikan dapat berkembang } \\
\text { menjadi besar dan berkembang biak. Hal ini menunjukan } \\
\text { bentuk konservasi ikan dan biota perairan lainnya. }\end{array}$ \\
\hline $\begin{array}{l}\text { Dilarang menyentrum atau } \\
\text { meracun ikan }\end{array}$ & $\begin{array}{l}\text { Pelarangan menyentrum dan meracun ikan dapat } \\
\text { membahayakan ekosistem dan manusia. Penggunaan arus } \\
\text { listrik maupun zat kimia tidak hanya melumpuhkan ikan } \\
\text { berukuran besar akan tetapi juga ikan berukuran kecil. Selain } \\
\text { itu, aliran listrik dan zat kimia juga dapat membunuh biota air } \\
\text { lainnya yang merupakan sumber makanan ikan. Matinya } \\
\text { biota air lainnya berpotensi merusak keseimbangan } \\
\text { ekosistem di Danau Bakuok. }\end{array}$ \\
\hline
\end{tabular}




\begin{tabular}{|c|c|}
\hline Sains Asli Masyarakat & Sains IImiah \\
\hline $\begin{array}{l}\text { Dilarang menanam sawit di } \\
\text { pinggiran danau bakuok }\end{array}$ & $\begin{array}{l}\text { Kelapa sawit (Elaeis guineensis) memiliki akar serabut } \\
\text { dangkal sehingga tidak memiliki kemampuan menyimpan air } \\
\text { yang baik dibanding pohon lainnya. Penanaman pohon sawit } \\
\text { secara berlebihan pada area danau berpotensi terhadap } \\
\text { pengurangan ketersediaan pasokan air terutama pada } \\
\text { musim kemarau(Taufiq et al., 2013) }\end{array}$ \\
\hline $\begin{array}{l}\text { Danau tidak dapat kering karena } \\
\text { dianggap sakti oleh masyarakat } \\
\text { setempat. }\end{array}$ & $\begin{array}{l}\text { Danau tidak dapat kering dikarenakan oleh beberapa faktor } \\
\text { yaitu debit air danau besar, tingginya tingkat produksi uap air } \\
\text { dan awan di daerah tersebut. Selain itu pohon-pohon } \\
\text { disekitaran danau berguna menyerap air hujan kemudian } \\
\text { menyimpannya sebagai air tanah, sehingga ketika musim } \\
\text { kemarau danau tidak kering. }\end{array}$ \\
\hline
\end{tabular}

Berdasarkan penjelasan di atas menunjukkan bahwa tradisi maauwo memiliki nilai pelestarian lingkungan. Rekonstruksi dari pengetahuan masyarakat ke pengetahuan ilmiah memberikan makna secara ilmiah dari aturan atau kepercayaan yang dimiliki masyarakat setempat. Sehingga pengetahuan ilmiah dapat digunakan sebagai sumber belajar terutama dalam pembelajaran IPA dan biologi. Siswa diharapkan dapat merekonstruksi pengetahuan yang diperoleh dari lingkungan sekitar menjadi pengetahuan ilmiah sehingga pembelajaran di kelas lebih bermakna. Dari Tabel 1 hasil rekonstruksi di atas didapatkan bahwa tradisi sains asli yang sudah dijelaskan ke dalam sains ilmiah. Dalam tradisi maauwo ini dapat dijadikan sebagai pembelajaran biologi.

Tabel 2. Potensi Kearifan Lokal Dalam Pembelajaran Biologi

\begin{tabular}{|c|c|c|}
\hline \multirow{2}{*}{$\begin{array}{lll}\text { Deskripsi Potensi } & \text { Kearifan } & \text { Lokal } \\
\text { dalam Pembelajaran Biologi } & \\
\end{array}$} & \multicolumn{2}{|c|}{ Keterkaitan dalam Pembelajaran Biologi } \\
\hline & KD Biologi & Materi \\
\hline $\begin{array}{l}\text { Danau Bakuok terbentuk akibat } \\
\text { terputusnya aliran Sungai Kampar } \\
\text { Kanan. Danau ini telah ditetapkan } \\
\text { sebagai danau adat yang berbasis } \\
\text { budaya dan memiliki aktivitas } \\
\text { perikanan. Semua kegiatan yang } \\
\text { dilaksanakan di Danau Bakuok ini } \\
\text { dikendalikan oleh Pemangku Adat. } \\
\text { Kegiatan penangkapan ikan hanya } \\
\text { boleh dilakukan } 1 \text { kali dalam } 1 \text { tahun } \\
\text { yang dinamakan sebagai tradisi } \\
\text { maawuo. Dengan adanya tradisi mauwo } \\
\text { tersebut dan juga peraturan adat yang } \\
\text { diterapkan seperti pelarangan dengan }\end{array}$ & 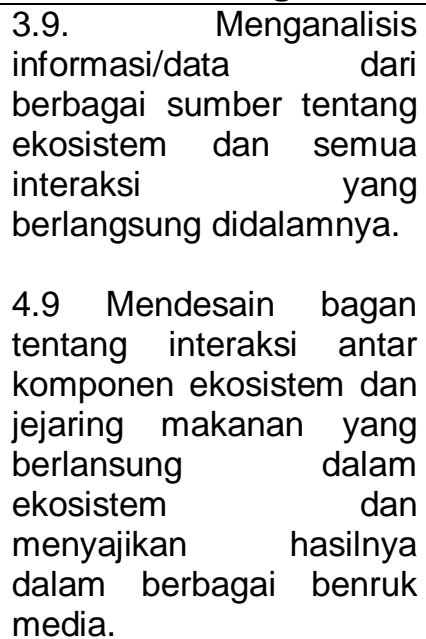 & $\begin{array}{l}\text { Ekologi } \\
\text { - } \quad \text { Komponen ekosistem } \\
\text { - } \quad \text { Aliran energi } \\
\text { - } \quad \text { Daur biogeokimia. } \\
\text { - } \quad \text { Interaksi dalam ekosistem }\end{array}$ \\
\hline $\begin{array}{l}\text { hanya boleh menangkap ikan dengan } \\
\text { alat tradisional, pelarangan menanam } \\
\text { pohon sawit di pinggiran danau dan } \\
\text { pelarangan membuat keramba di danau } \\
\text { bakuok maka potensi yang dapat }\end{array}$ & $\begin{array}{l}\text { 3.10. Menganalisis data } \\
\text { perubahan lingkungan } \\
\text { dan dampak dari } \\
\text { perubahan perubahan } \\
\text { tersebut bagi kehidupan. }\end{array}$ & $\begin{array}{l}\text { Keseimbangan lingkungan } \\
\text { - Kerusakan lingkungan/ } \\
\text { pencemaran lingkungan. } \\
\text { - Pelestarian lingkungan }\end{array}$ \\
\hline $\begin{array}{l}\text { digunakan dalam Pembelajaran biologi } \\
\text { yaitu: }\end{array}$ & $\begin{array}{lr}4.10 . & \text { Memecahkan } \\
\text { masalah lingkungan } \\
\text { dengan membuat desain }\end{array}$ & \\
\hline
\end{tabular}




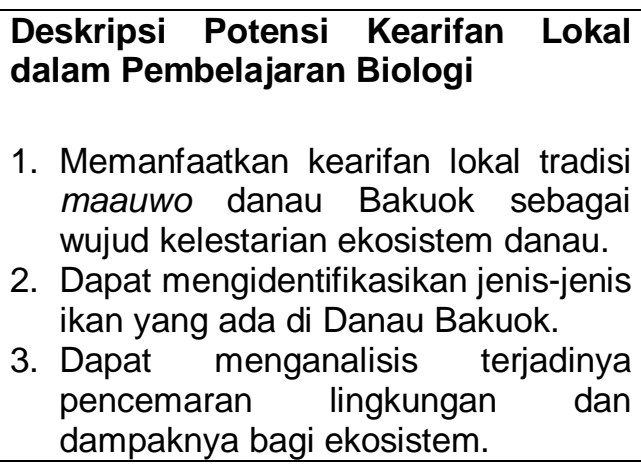

1. Memanfaatkan kearifan lokal tradisi maauwo danau Bakuok sebagai wujud kelestarian ekosistem danau.

2. Dapat mengidentifikasikan jenis-jenis ikan yang ada di Danau Bakuok.

3. Dapat menganalisis terjadinya pencemaran lingkungan dan dampaknya bagi ekosistem.

\begin{tabular}{|l|c|}
\hline \multicolumn{2}{|c|}{ Keterkaitan dalam Pembelajaran Biologi } \\
\hline KD Biologi & Materi \\
\hline $\begin{array}{l}\text { produk daur ulang limbah } \\
\text { dan upaya pelestarian } \\
\text { lingkungan. }\end{array}$ \\
\\
\end{tabular}

Pembelajaran biologi sangat relevan dikaitkan dengan kearifan lokal tentang alam sekitar karena pada hakikatnya pembelajaran biologi terkonsentrasi pada lingkungan sekitar (Tillery et al., 2011). Sehingga pemanfataan kearifan lokal seperti tradisi Maauwo di Danau Bakuok dalam pembelajaran biologi dapat membantu siswa memahami konsep sains melalui isu konteksual yang berhubungan erat dengan kehidupan siswa.

\section{SIMPULAN DAN SARAN}

Tradisi Maauwo adalah sebuah tradisi masyarakat Kampar untuk menangkap ikan di danau Bakuok secara bersama-sama. Tradisi maauwo sebagai salah bagian dalam sistem pengelolaan sumber daya peraiaran di danau bakuok. Masyarakat dilarang mengambil ikan dalam periode tertentu, dilarang untuk menyentrum maupun meracun ikan serta menanami sawit di tepi danau tersebut. Penerapan aturan tersebut memiliki nilai konservasi lingkungan untuk menjaga keseimbangan ekosistem di danau bakuok. Kearifan lokal ini memiliki potensi yang dapat digunakan sebagai sumber pembelajaran biologi.

\section{UCAPAN TERIMA KASIH}

Terimakasih kepada Kepala Adat dan Kepala Desa Aursati yang telah memberikan informasi kepada peneliti mengenai tradisi maauwo yang ada di Danau Bakuok.

\section{RUJUKAN}

Battiste, M. (2005). Indegenous Knowledge: Foundation for First Nations. University of Saskatchewan.

Brata, I. B. (2016). Kearifan Budaya Lokal Perekat Identitas Bangsa. Jurnal Bakti Saraswati, 05(01). http://jurnal.unmas.ac.id/index.php/Bakti/article/view/226

Diskominfo. (2020). Informasi Umum Provinsi riau. https://www.riau.go.id/home/content/61/data-umum

Elsera, M. (2019). Suku Laut di Dusun Linau Batu Desa Tanjungkelit, Kabupaten Lingga Provinsi Kepri. Sosioglobal: Jurnal Pemikiran Dan Penelitian Sosiologi, 3(2), 1. https://doi.org/10.24198/jsg.v3i2.21054

Harefa, A. R. (2017). Pembelajaran Fisika Di Sekolah Melalui Pengembangan Etnosains. Jurnal Warta Edisi, 53, 1-18.

Hergenhanh, B. R., \& Olson, M. H. (2008). Teories of Learning (7 ed). Kencana. Irawan, B., \& Muhartati, E. (2019). Identifikasi Nilai Etnosains pada Kearifan Lokal 
Berkarang dan Menyondong Ikan Pada Masyarakat Pesisir Bintan. Pedagogi Hayati, 3(1), 53-58. https://doi.org/10.31629/ph.v3i1.1595

Mulyani, M., \& Julianto, J. (2019). Pembelajaran Sains Berbasis Budaya Lokal Sebagai Bentuk Integratif Pendidikan Karakter. EduStream: Jurnal Pendidikan Dasar, 2(1), 35-42. https://journal.unesa.ac.id/index.php/jpd/article/view/6261

Oktavianti, I. (2018). Media Berbasis Kearifan Lokal. Jurnal Refleksi Edukatika, 8(2).

Pieter, J. (2017). Pembelajaran IPA Berbasis Kearifan Lokal Sebagai Solusi Pengajaran IPA di Daerah Pedalaman Provinsi Papua. https://www.researchgate.net

Rahayu, W. E., \& Sudarmin. (2015). Pengembangan Modul Ipa Terpadu Berbasis Etnosains Tema Energi Dalam Kehidupan Untuk Menanamkan Jiwa Konservasi Siswa. Unnes Science Education Journal, 4(2), 919-926.

Rahmi, D. A., \& Rosdiana, L. (2018). Peningkatan Hasil Belajar Dengan Menggunakan Media Science Story Berbasis Etnosains. Ejournal-Pensa, 6(2), 108-113.

Snively, G., \& Corsiglia, J. (2001). Discovering Indigenous Science: Implications for Science Education. National Association of Research in Science Teaching.

Sudjana, N., \& Rivai, A. (2007). Teknologi Pengajaran. Sinar Baru Algesindo.

Taufiq, M., Siswoyo, H., \& Anggara, W. (2013). Pengaruh Tanaman Kelapa Sawit Terhadap Keseimbangan Air Hutan (Studi Kasus Sub Das Landak, Das Kapuas). Jurnal Teknik Pengairan, 4(1). https://jurnalpengairan.ub.ac.id/index.php/jtp/article/view/180

Thamrin, H. (2014). Revitalisasi Kearifan Lokal Melayu Dalam Menjaga Harmonisasi Lingkungan Hidup. TOLERANSI: Media Komunikasi Umat Bergama, 6(1), 90106.

Tillery, B., Enger, E. D., \& Ross, F. C. (2011). Integrated science. McGraw-Hill.

Yuliana, I. (2017). Pembelajaran Berbasis Etnosains Dalam Mewujudkan Pendidikan Karakter Siswa Sekolah Dasar. ELSE (Elementary School Education Journal): Jurnal Pendidikan Dan Pembelajaran Sekolah Dasar, 1(2015), 98-106. 